\title{
RANCANG BANGUN PERANGKAT PEMANTAU CUACA OTOMATIS BERBASIS MIKROKONTROLER PADA JARINGAN WLAN IEEE 802.11b
}

\author{
Willy Sucipto $^{1}$, I G. A. K. Diafari Djuni Hartawan ${ }^{2}$, Widyadi Setiawan ${ }^{3}$ \\ Program Studi Teknik Elektro, Fakultas Teknik, Universitas Udayana \\ Email: willysucipto21@gmail.com ${ }^{1}$, igakdiafari@unud.ac.id ${ }^{2}$, widyadi@unud.ac.id $^{3}$
}

\begin{abstract}
ABSTRAK
Penelitian ini bermaksud untuk merancang dan membangun perangkat pemantau cuaca otomatis berbasis mikrokontroler yang dapat memantau perubahan suhu, kelembaban, tekanan udara, arah dan kecepatan angin melalui sensor-sensor yang telah diletakan pada lokasi pemantauan cuaca. Fleksibilitas alat pemantau cuaca ini dimaksudkan agar operator yang memantau cuaca dapat memantau cuaca dan mengolah datanya dari manapun. Untuk menambah fleksibilitas maka data hasil sensor yang diolah pada mikrokontroler wemos akan dikoneksikan dengan access point di jaringan nirkabel 2,4 GHz, kemudian data akan dikirim ke web server. Data-data sensor tersebut selain dikirim ke internet akan disimpan juga pada SD Card sebagai sistem cadangan data dalam bentuk data logger. Hasil pengujian alat menyatakan bahwa alat telah beroperasi dengan baik dan dapat digunakan untuk memantau cuaca.
\end{abstract}

Kata Kunci : Data logger, nirkabel, Pemantau Cuaca Otomatis, sensor, wemos, web server.

\section{ABSTRACT}

This research intends to build an automatic weather monitoring device based on microcontroller that can monitor changes in temperature, humidity, air pressure, wind direction and velocity through the sensors that have been placed on the weather monitoring location. The flexibility of this weather monitoring tool is intended to allow weather forecaster operators to monitor weather and process data from anywhere. To increase the flexibility of the sensor data processed on wemos microcontroller will be connected with access points in $2.4 \mathrm{GHz}$ wireless network, then the data will be sent to the web server. Sensor data in addition to sent to the internet will also be stored on the SD Card as a data backup system in the form of data loggers. The device test results state that the tool has been operating properly and can be used to monitor the weather.

Keywords : Automatic Weather Monitor, data logger, sensor, wireless, wemos, web server.

\section{PENDAHULUAN}

Pengamatan unsur cuaca sangat diperlukan untuk kesejahteraan dan keperluan manusia. Unsur cuaca yang diamati akan dijadikan bahan untuk memprakirakan cuaca pada waktu yang akan datang. Data unsur cuaca ini sangat berguna untuk mengetahui klimatologis suatu daerah, sehingga manusia dapat memanfaatkan kondisi cuaca tersebut sesuai kebutuhan masing-masing pihak. Data cuaca juga bisa dimanfaatkan untuk mengurangi atau bahkan menghindari resiko akibat buruknya cuaca tersebut.

Badan Meteorologi Klimatologi dan Geofisika (BMKG) merupakan instansi pemerintah yang ditugaskan untuk mengamati cuaca dan memberikan prakiraan cuaca serta peringatan dini yang berhubungan dengan cuaca. Dalam proses pengamatan cuaca diperlukan instrumen yang akan ditempatkan dalam suatu lokasi tertentu untuk mewakili kondisi lingkungan daerah sekitarnya yang disebut sebagai stasiun cuaca [1].

Sebuah stasiun cuaca otomatis (automatic weather station) merupakan instrumen yang mengukur dan mencatat parameter meteorologi menggunakan sensor. Sensor ini yang berfungsi sebagai alat ukur untuk mengukur setiap perubahan cuaca tersebut. Data hasil keluaran dari sensor akan diproses di data logger dan kemudian dikirimkan ke stasiun cuaca BMKG sehingga dapat diakses oleh user 
ataupun orang yang membutuhkan data stasiun cuaca. [2].

Sensor-sensor akan ditempatkan di suatu area dalam jangkauan WiFi untuk memproses hasil pantauan cuaca di daerah tersebut. Data yang didapat dari sensorsensor tersebut, yang kemudian akan dikirimkan langsung melalui perangkat WiFi yang terhubung ke web server. Selain dikirim langsung ke web server, data juga akan disimpan di data logger sebagai back up system [3].

Pada penelitian ini akan direalisasikan alat untuk mengukur suhu, kelembaban, tekanan udara, serta arah dan kecepatan angin berbasis mikrokontroler. Pada penelitian sebelumnya proses distribusi data hanya menggunakan komunikasi kabel ataupun menggunakan transmisi nirkabel tetapi dengan jarak yang relatif dekat. Pengiriman data pada perangkat ini dengan jaringan WiFi, sehingga data dapat didistribusikan secara luas. Dengan menggunakan sistem web server ini bisa diakses oleh lebih banyak pengguna.

\section{KAJIAN PUSTAKA \\ 2.1 Mikrokontroler}

Mikrokontroler adalah sebuah computer kecil di dalam suatu IC (Integrated Circuit) yang berisi memory, timer, saluran komunikasi serial dan paralel, port input dan output, dan ADC. Mikrokontroler digunakan untuk suatu tugas dan menjalankan suatu program [4]. WEMOS adalah pengendali mikro single-board yang bersifat opensource. Wemos merupakan salah satu mikrokontroler yang kompatibel dengan arduino sehingga software yang digunakan adalah software arduino IDE yang dirancang khusus untuk keperluan IOT (internet of things). Wemos menggunakan chip SoC (system on a chip) WiFi yang cukup terkenal saat ini yaitu ESP8266.

\subsection{Web server}

Web server digunakan untuk menjadi sarana menampilkan data. Dalam pelaksanaanya web server menggunakan protokol komunikasi sebagai sarananya seperti, alamat website pada jaringan internet. [5] Pada alat ini menggunakan thingspeak.com sebagai web servernya. Thingspeak.com mendukung tampilan data hasil sensor dalam bentuk grafik, file excel dan data mentah. Web server ini juga mudah untuk diakses, yang dibutuhkan hanya akun thingspeak.com untuk membuat channel baru. Setelah membuat channel baru maka pengguna akan mendapatkan AP Key sebagai kode untuk masuk akun sebagai admin channel sendiri. AP Key ini yang akan digunakan perangkat mikrokontroler untuk masuk ke akun thingspeak.com.

\subsection{Automatic Weather Station}

Automatic Weather Station (AWS) didefenisikan sebagai stasiun meteorologi yang melakukan pengamatan dan mengirim secara otomatis [6]. Pada umumnya AWS dilengkapi dengan beberapa sensor antara lain :

a. Termometer untuk mengukur Suhu

b. Anemometer untuk mengukur Arah dan Kecepatan angin

c. Hygrometer merupakan alat untuk mengukur Kelembaban

d. Barometer untuk mengukur Tekanan Udara

e. Rain gauge untuk mengukur Curah Hujan

f. Pyranometer untuk mengukur Penyinaran Matahari

Data hasil pengukuran dari masingmasing AWS dapat diproses pada lokasi AWS itu sendiri atau dikumpulkan pada unit pusat data akuisisi, kemudian data yang dikumpulkan secara otomatis diteruskan ke pusat pengolahan data untuk dipergunakan sesuai kebutuhan. [7] Automatic Weather Station dapat didesain secara terintegrasi dengan beberapa AWS lain sehingga membentuk suatu system pengamatan yang dikenal dengan Automated Weather Observing System (AWOS).

\section{METODE PENELITIAN}

\subsection{Tahapan Penelitian}

Langkah-langkah penelitian yang dilakukan untuk membangun perangkat pemantau cuaca berbasis mikrokontroler adalah sebagai berikut :

1. Melakukan analisis permasalahan dari perangkat yang akan dibangun.

2. Melakukan studi literatur dengan mengumpulkan refrensi yang diperoleh dari berbagai sumber literatur untuk membangun perangkat ini.

3. Merancang setiap blok diagram sistem.

4. Perancangan Hardware setiap blok rangkaian.

5. Perancangan software setiap blok rangkaian 
6. Uji Coba setiap blok rangkaian.

7. Menggabungkan setiap blok rangkaian

8. Merancang sistem pemantau cuaca.

9. Uji coba keseluruhan sistem

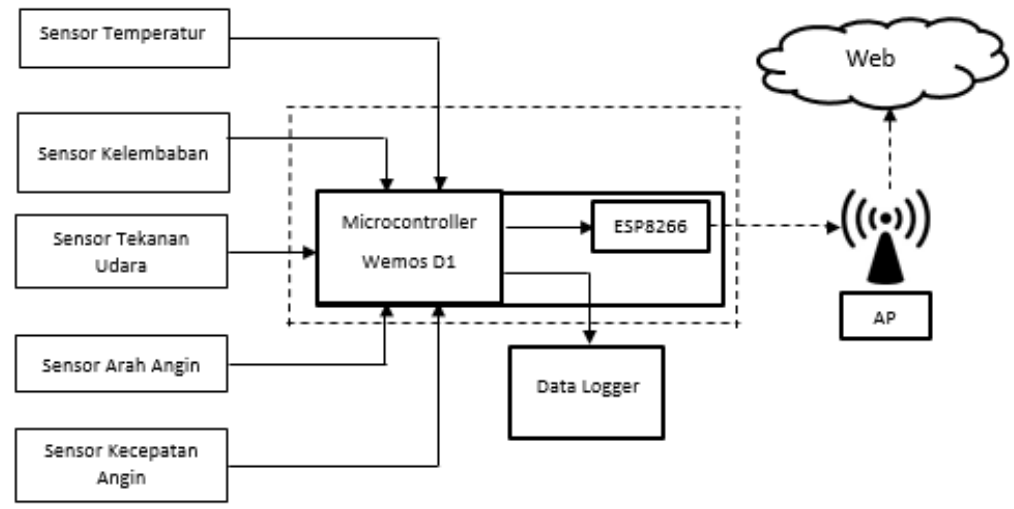

Gambar 1. Diagram Blok Sistem Perangkat Pemantau Cuaca

Tabel 1 Penggunaan pin pada perangkat secara keseluruhan

\begin{tabular}{|c|c|c|}
\hline Perangkat & Pin pada wemos & Kode pada arduino IDE \\
\hline DHT22 & D4 & 2 \\
\hline BMP180 & SDA, SCL & SDA, SCL \\
\hline LM393 & A0 & A0 \\
\hline 2SS52M & RX, D0, D2, D6 & $3,16,4,12$ \\
\hline SD Card & D5, D6, D7, D8 & $14,12,13,15$ \\
\hline RTC & SDA, SCL & SDA, SCL \\
\hline
\end{tabular}

\subsection{Gambaran Umum}

Perangkat pemantau cuaca ini berbasis mikrokontroler Wemos D1 dengan pemrograman menggunakan Software Arduino IDE dan transmisi yang digunakan dalam penggunaan alat ini adalah jaringan IEEE 802.11. Perangkat ini menggunakan 4 jenis sensor yaitu DHT22 sebagai sensor kelembaban, sensor BMP180 sebagai sensor suhu dan tekanan udara, sensor LM393 sebagai sensor kecepatan angin dan sensor 2SS52M sebagai sensor arah angin. Data yang diterima sensor akan dikirim melalui modul ESP8266 dan juga data akan di simpan di SD Card dalam bentuk data logger.

\subsection{Pemodelan Sistem}

Pemodelan sistem perangakat pemantau cuaca berbasis mikrokontroler dengan menggunakan jaringan WLAN IEEE 802.11b akan dijelaskan pada Gambar 1.

Data sensor yang di hasilkan oleh sensor akan di transmisikan melalui
ESP8266 ke web server dengan jaringan IEEE 802.11b (WiFi). Selain dikirimkan, data juga akan disimpan di data logger untuk menghindari jika terdapat data yang hilang saat pengiriman.

\subsection{Perancangan Hardware}

Perancangan Hardware alat pemantau cuaca otomatis menggunakan mikrokontroler wemos D1. Wemos mempunyai pin-pin digital dan analog sebagai input output data. Penggunaan pin untuk sensor-sensor dan data logger dapat dilihat pada Tabel 1 di bawah ini. Karena perangkat yang digunakan adalah wemos dan software yang digunakan adalah arduino maka nama pin pada software harus disesuaikan agar kompatibel..

Rangkaian alat keseluruhan sebelum dirangkai pada PCB masih harus diuji coba pada bread board. Rangkaian keseluruhan alat dapat dilihat pada Gambar 2 dibawah ini 


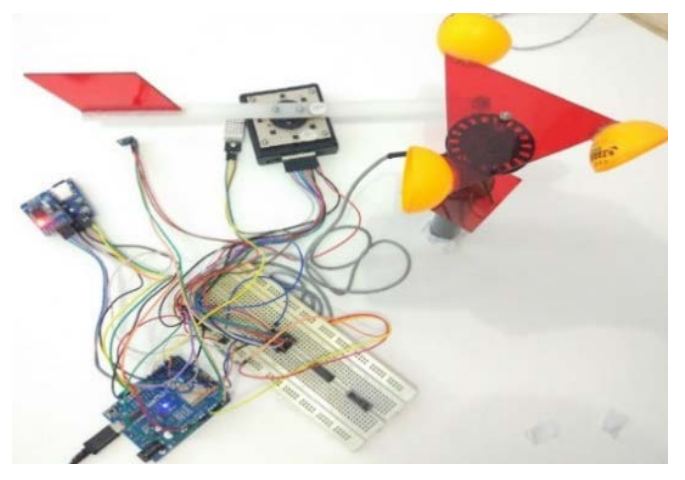

\section{HASIL DAN PEMBAHASAN}

\subsection{Hasil Penelitian}

Hasil dari penelitian "Rancang Bangun Perangkat Pemantau Cuaca Otomatis Berbasis Mikrokontroler Pada Jaringan WLAN IEEE 802.11b" ini adalah berupa tampilan pada web server dan tampilan pada data logger.

Rangkaian perangkat automatic weather station secara keseluruhan merupakan gabungan dari blok rangkaian sensor, rangkaian data logger dan mikrokontroler. Mikrokontroler yang digunakan adalah wemos. Wemos ini sebelum beroperasi akan diunggah program terlebih dahulu menggunakan USB tipe c.

Sensor yang dirangkai pada PCB mempunyai fungsinya masing-masing, sensor DHT22 untuk mengukur kelembaban sensor BMP180 untuk mengukur suhu dan tekanan udara, sensor LM393 untuk mengukur kecepatan angin dan sensor 2SS52M untuk mengukur arah angin. Semua sensor mendapat tegangan yang sama dari wemos yaitu $5 \mathrm{~V}$.

Pada perangkat ini menggunakan baterai $9 \mathrm{~V}$ atau yang biasa disebut baterai kotak. Cara penggunaan baterai ini yaitu dengan dimasukan ke dalam battery holder, kemudian dihubungkan ke rangkaian alat. Penggunaan baterai ini setelah program selesai diunggah ke mikrokontroler wemos.

Semua komponen yang telah dirakit pada PCB akan didapat dilihat pada Gambar 3.

\section{Gambar 2. Rancangan Hardware pada breadboard}

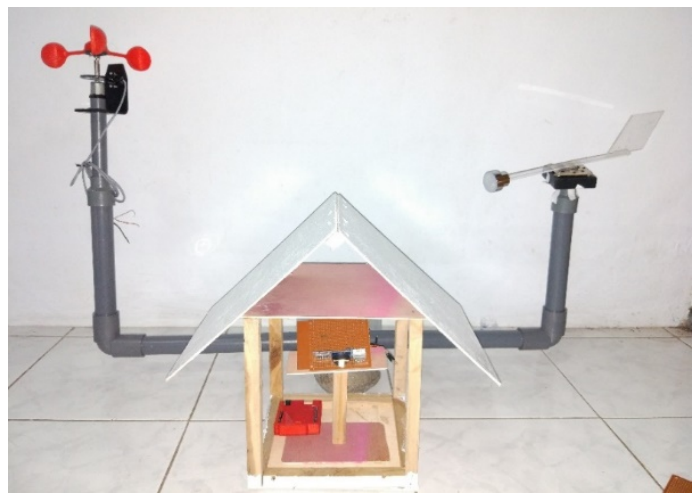

Gambar 3. Hasil Rancangan Keseluruhan Perangkat

\subsection{Pembahasan Perangkat}

Pembahasan perangkat akan dilakukan dengan melakukan transmisi data sensor ke web server dan data juga akan disimpan pada data logger.

\subsubsection{Pengiriman data ke Web server}

Untuk penyajian data digunakan web server thingspeak.com, yang akan menampilkan hasil sensor dalam bentuk grafik. Wemos D1 sudah dilengkapi dengan SoC WiFi ESP8266 sehingga data yang didapat dari sensor akan dikirim melalui jaringan WiFi melalui acces point, kemudian dikirim ke Web server.

Pengujian dilakukan selama 2 jam. Dari hasil pengujian didapat data hasil pada grafik yang ditampilkan pada public view thingspeak.com.

Gambar 4 adalah grafik temperature. Pada grafik temperatur terlihat perubahan suhu mulai dari $26.1^{\circ} \mathrm{C}$ sampai $26.7^{\circ} \mathrm{C}$. 


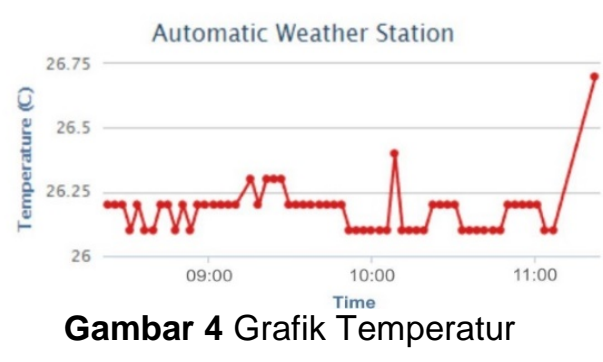

Gambar 5 merupakan grafik tekanan udara yang datanya di ambil selama 2 Jam dan pada grafik terlihat perubahan tekanan mulai dari $979 \mathrm{mb}$ sampai $982 \mathrm{mb}$.

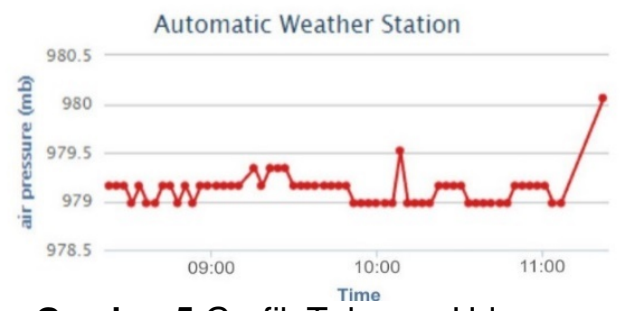

Gambar 5 Grafik Tekanan Udara

Gambar 6 merupakan grafik kelembaban yang datanya di ambil selama 2 jam dan pada grafik terlihat perubahan kelembaban mulai dari 55\% sampai 58.5\%.

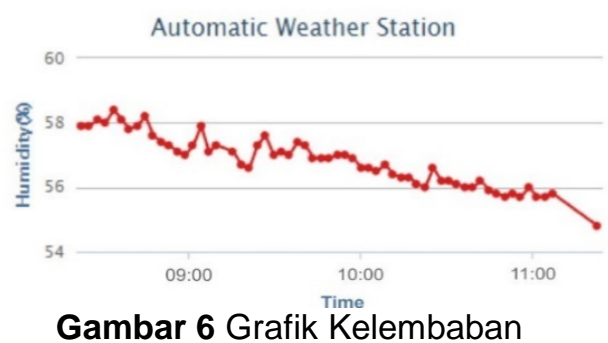

Gambar 7 merupakan grafik arah angin yang datanya di ambil selama 2 jam. Angka 1 adalah arah utara, 2 adalah timur laut, 3 adalah timur, 4 adalah tenggara, 5 adalah selatan, 6 adalah barat daya, 7 adalah barat, 8 adalah barat laut. Pada grafik terlihat perubahan arah ke arah timur laut.

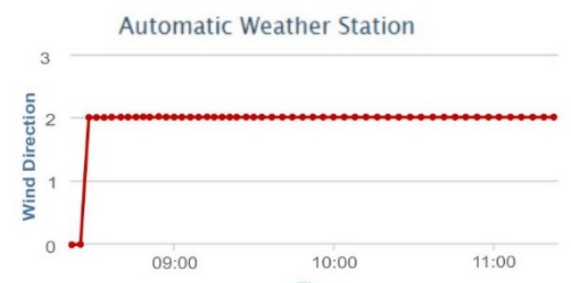

Gambar 7 Grafik Arah Angin
Gambar 8 merupakan grafik kecepatan angin yang datanya di ambil selama 2 jam dan pada grafik terlihat perubahan kecepatan mulai dari $0 \mathrm{~m} / \mathrm{s}-8$ $\mathrm{m} / \mathrm{s}$.

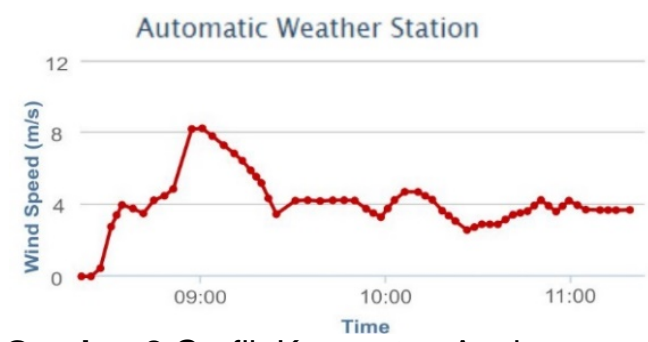

Gambar 8 Grafik Kecepatan Angin

\subsubsection{Penyimpanan pada Data logger}

Selain dikirimkan ke web server, datadata sensor tersebut juga kan disimpan secara offline pada data logger. Rangkaian data logger sendiri terdiri dari modul SD card untuk menyimpan data dan modul real time clock untuk menyesuaikan dengan waktu pengambilan data.

Data keluaran sensor beserta waktu pengambilan data disediakan dalam file .csv sehingga untuk membukanya kita bisa menggunakan microsoft excel. Sampel data yang yang diambil dapat dilihat pada Gambar di bawah ini.

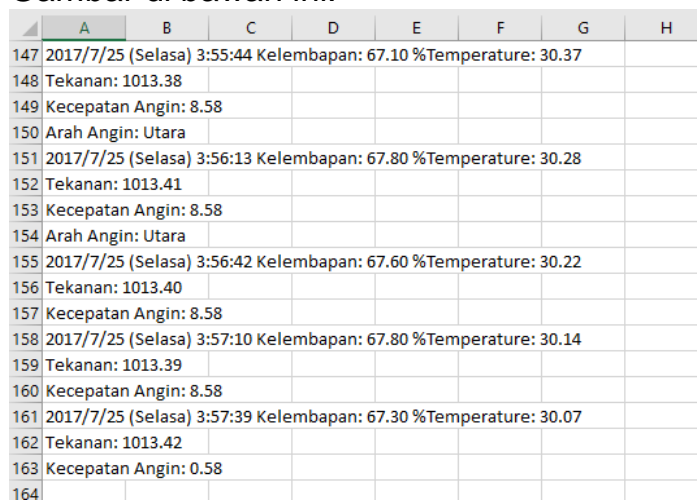

Gambar 8 hasil data untuk pengujian Data logger

\subsection{Kalibrasi Perangkat}

kalibrasi yang dilakukan pada perangkat adalah dengan membandingkan sensor-sensor dengan standar BMKG. Kalibrasi dilakukan agar alat mempunyai ketelitian yang mendekati standar. Sensor akan dimasukan kedalam chamber bersama sensor dari BMKG sebagai pembandingnya, lalu kedua sensor akan dibandingkan perubahan dan ketelitiannya.

a.

Sensor Suhu 
Data hasil kalibrasi sensor suhu DHT dapat dilihat pada Tabel 2 berikut dan dapat diketahui bahwa nilai ketidakpastian alat rata-rata adalah 0.33 .

Tabel 2 Data Kalibrasi Sensor Suhu

\begin{tabular}{|c|c|c|c|}
\hline $\begin{array}{c}\text { Suhu Standar } \\
\left({ }^{\circ} \mathbf{C}\right)\end{array}$ & $\begin{array}{c}\text { Alat yang } \\
\text { dikalibrasi }\left({ }^{\circ} \mathbf{C}\right)\end{array}$ & $\begin{array}{c}\text { Koreksi } \\
\left({ }^{\circ} \mathbf{C}\right)\end{array}$ & $\begin{array}{c}\text { Ketidakpastian } \\
\left({ }^{\circ} \mathbf{C}\right)\end{array}$ \\
\hline 19.990 & 20.05 & -0.06 & 0.33 \\
\hline 30.000 & 29.85 & 0.15 & 0.33 \\
\hline 40.039 & 39.76 & 0.28 & 0.33 \\
\hline
\end{tabular}

b. Sensor Kelembaban

Data hasil kalibrasi sensor kelembaban DHT dapat dilihat pada Tabel 3 berikut dan dapat diketahui bahwa nilai ketidakpastian alat rata-rata adalah 1.09.

Tabel 3 Data Kalibrasi Sensor Kelembaban

\begin{tabular}{|c|c|c|c|}
\hline $\begin{array}{c}\text { RH Standar } \\
(\%)\end{array}$ & $\begin{array}{c}\text { RH alat yang } \\
\text { dikalibrasi (\%) }\end{array}$ & $\begin{array}{c}\text { Koreksi } \\
(\%)\end{array}$ & $\begin{array}{c}\text { Ketidakpastian } \\
(\%)\end{array}$ \\
\hline 40.98 & 42.01 & 1.03 & 1.08 \\
\hline 59.78 & 60.85 & 1.07 & 1.4 \\
\hline 76.98 & 79.39 & 0.97 & 0.79 \\
\hline
\end{tabular}

\section{c. Sensor Tekanan Udara}

Data hasil kalibrasi sensor tekanan BMP180 dapat dilihat pada Tabel 4 berikut dan dapat diketahui bahwa nilai ketidakpastian alat rata-rata adalah 0.22 .

Tabel 4 Data Kalibrasi Sensor tekanan

\begin{tabular}{|c|c|c|c|}
\hline $\begin{array}{c}\text { Tekanan } \\
\text { Standar }(\mathbf{m b})\end{array}$ & $\begin{array}{c}\text { Tekanan alat yang } \\
\text { dikalibrasi }(\mathbf{m b})\end{array}$ & $\begin{array}{c}\text { Koreksi } \\
(\mathbf{m b})\end{array}$ & $\begin{array}{c}\text { Ketidakpastian } \\
(\mathbf{m b})\end{array}$ \\
\hline 851.11 & 851.25 & -0.07 & 0.21 \\
\hline 900.84 & 900.99 & -0.08 & 0.23 \\
\hline 950.41 & 950.82 & -0.06 & 0.22 \\
\hline 1000.35 & 1000.53 & -0.06 & 0.24 \\
\hline 1049.60 & 1049.78 & -0.07 & 0.24 \\
\hline
\end{tabular}

\section{d. Sensor Kecepatan Angin}

Data hasil kalibrasi sensor kecepatan angin LM393 dapat dilihat pada Tabel 5 berikut dan dapat diketahui bahwa nilai ketidakpastian alat rata-rata adalah 0.51 .

Tabel 5 Data Kalibrasi Sensor Kecepatan Angin

\begin{tabular}{|c|c|c|c|}
\hline $\begin{array}{c}\text { Kecepatan } \\
\text { angin Standar } \\
(\mathbf{m} / \mathbf{s})\end{array}$ & $\begin{array}{c}\text { Kecepatan } \\
\text { angin alat yang } \\
\text { dikalibrasi (m/s) }\end{array}$ & $\begin{array}{c}\text { Koreksi } \\
\mathbf{( m / s )}\end{array}$ & $\begin{array}{c}\text { Ketidakpastian } \\
(\mathbf{m} / \mathbf{s})\end{array}$ \\
\hline 2.06 & 2.1 & 0.04 & 0.04 \\
\hline 7.04 & 8.5 & 1.46 & 1.46 \\
\hline 15.07 & 15.05 & -0.02 & 0.02 \\
\hline
\end{tabular}

$$
\text { e. }
$$

Sensor Arah Angin

Data hasil kalibrasi sensor arah angin 2SS52M dapat dilihat pada Tabel 6 berikut dan dapat diketahui bahwa nilai ketidakpastian alat rata-rata adalah 0.02 .

Tabel 6 Data kalibrasi sensor arah angin

\begin{tabular}{|c|c|c|c|}
\hline $\begin{array}{c}\text { Arah angin } \\
\text { Standar }\left({ }^{\circ}\right)\end{array}$ & $\begin{array}{c}\text { Arah angin alat } \\
\text { yang dikalibrasi }\left({ }^{\circ}\right)\end{array}$ & $\begin{array}{c}\text { Koreksi } \\
\left(\mathbf{(}^{\circ}\right)\end{array}$ & $\begin{array}{c}\text { Ketidakpastian } \\
\left(\mathbf{(}^{\circ}\right)\end{array}$ \\
\hline 0 & 0 & 0 & 0 \\
\hline 90 & 89.8 & -0.2 & 0.2 \\
\hline 180 & 179.8 & -0.2 & 0.2 \\
\hline 270 & 269.8 & -0.2 & 0.2 \\
\hline
\end{tabular}

Berdasarkan data hasil kalibrasi yang dilakukan pada setiap sensor yang digunakan dapat diketahui bahwa, sensorsensor yang digunakan cukup layak untuk dioperasikan untuk pemantauan cuaca karena faktor koreksi terhadap sensor pembanding yang relatif kecil.

\subsection{Pengujian Perangkat}

Pengujian perangkat dilakukan dengan mencari maksimum WiFi ini dengan mengkondisikan wemos sebagai acces point. Tempat pengujian adalah Lapangan Gelora Trisakti, Badung, Bali dan pengujian dilakukan pada malam hari. Untuk pengujian jangkauannya menggunakan aplikasi GNET WiFi dan Google Earth sebagai aplikasi untuk menampilkan hasil pengujian.

Secara teori jangkauan WiFi dapat dicari dengan mempertimbangkan free space path loss, power transmitter, receiver, dan parameter-parameter lainnya. Untuk mengetahui jangkauan alat secara teori dapat dilakukan perhitungan sebagai berikut dengan asumsi loss transmitter, gain transmitter dan gain receiver bernilai 0 , karena pada data sheet tidak tertera parameter tersebut. Dari perhitungan secara teori didapatkan bahwa jangkauan maksimum perangkat dalam memancarkan WiFi adalah sebesar 295 meter.

Hasil pengujian yang dilakukan dengan menggunakan software GNET WiFi dapat dilihat pada Tabel 7 berikut. Dari Tabel 7 dapat diketahui bahwa jarak jangkauan maksimum dari perangkat pemantau cuaca otomatis ini adalah sebesar 126,5 meter. Nilai RSSI minimum yang didapatkan pun sebesar $-85 \mathrm{dBm}$. Lebih besar dari yang tertera pada data sheet yaitu $-91 \mathrm{dBm}$. Nilai jarak jangkau ini jauh lebih kecil jika dibandingkan dengan perhitungan secara teori, dimana jangkauan maksimum perangkat secara teori adalah 295 meter. Hal ini dikarenakan secara teori masih ada faktor yang dimasukkan dalam perhitungan.

Tabel 7 Data kalibrasi sensor arah angin

\begin{tabular}{|c|c|}
\hline Jangkauan (m) & RSSI (dBm) \\
\hline 3 & -39 \\
\hline
\end{tabular}




\begin{tabular}{|c|c|}
\hline 4.5 & -39 \\
\hline 8.4 & -55 \\
\hline 14.5 & -66 \\
\hline 20.7 & -69 \\
\hline 26.9 & -69 \\
\hline 32.4 & -69 \\
\hline 37.9 & -76 \\
\hline 44.2 & -78 \\
\hline 49.9 & -79 \\
\hline 54.5 & -79 \\
\hline 60.7 & -79 \\
\hline 66.7 & -80 \\
\hline 71.6 & -80 \\
\hline 77.8 & -80 \\
\hline 83.3 & -80 \\
\hline 88.0 & -80 \\
\hline 93.5 & -82 \\
\hline 101.3 & -83 \\
\hline 108.2 & -84 \\
\hline 114.2 & -84 \\
\hline 120.0 & -83 \\
\hline 126.5 & -85 \\
\hline 126.7 & -127 \\
\hline
\end{tabular}

\section{KESIMPULAN}

Setelah melakukan perancangan dan pengujian pada perangkat, maka penelitian ini dapat disimpulkan bahwa,

1. Perangkat Pemantau Cuaca Otomatis Berbasis Mikrokontroler Wemos pada Jaringan IEEE 802.11b mempunyai fleksibilitas dan tingkat presisi yang baik. Dikatakan fleksibel karena peletakan alat dapat dilakukan di berbagai tempat. Dengan hasil kalibrasi sensor yang mempunyai nilai koreksi di bawah nilai yang ditentukan BMKG yaitu 2 maka sensor-sensor tersebut dikatakan memiliki presisi yang baik.

2. Transmisi wireless yang digunakan mempunyai batas jangkauan, sehingga untuk mengetahui batas jangkauan perangkat dilakukan pengujian secara teori dan praktek. Secara teori nilai jangkauan perangkat terkoneksi dengan acces pointnya sampai jarak 295 meter sedangkan pada pengukuran teknisnya jarak terjauhnya adalah 127 meter.

3. Apabila terjadi kesalahan pada sistem transmisi, maka terdapat sistem back up yaitu dengan menggunakan SD card sebagai data loger. Dengan pengujian yang dilakukan selama 2 jam terlihat bahwa selalu terjadi fluktuasi terhadap nilai sensor-sensor yang digunakan.

\section{SARAN}

Berdasarkan hasil rancang bangun perangkat automatic weather station (AWS), maka untuk pengembangan lebih lanjut ada saran agar sistem AWS ini dapat bekerja dengan baik.

1. Pada sistem transmisi masih menggunakan web server thingspeak.com sehingga file masih dapat diketahui oleh provider atau pihak pengelola thingspeak sehingga keamanan file masih kurang terjamin, sehingga diperlukan web server sendiri agar kemanan data lebuh terjamin.

2. Daya yang digunakan didapat dari baterai, dan hanya bertahan kurang dari 24 jam, sehingga untuk pegembangan selanjutnya diharapkan agar menggunakan sumber daya lain yang dpat diperharui seperti solar sel atau kincir angin sebagai sumber daya.

3. Untuk fleksibilitas yang lebih baik lagi, maka sistem transmisi yang digunakan dapat dikembangkan dengan media trsansmisi menggunakan jaringan GPRS, 3G dan jaringan seluler lain sehingga tidak memerlukan tambahan router, hal ini juga memungkikan karena ukuran data yang ditransmisikan relatif kecil.

\section{DAFTAR PUSTAKA}

[1] Republik Indonesia. Undang-Undang tentang Meteorologi, Klimatologi, dan Geofisika. 2009, Jakarta: Sekretariat Negara, 2009.

[2] Salindri, Zeta Hanif. Rancang Bangun Mini Weather Station Menggunakan Web Berbasis Arduino Atmega 2560. Jurnal IImiah Teknik Elektro Transient. 2015: Vol 4. No 4.

[3] Hidayat I, Esti P, Rancang Bangun Sistem Telemetri dan Monitoring Stasiun Cuaca Secara Nirkabel Berbasis Mikrokontroler, Seminar Nasional Informatika 2012, Yogyakarta. 2012: ISSN: 1979-2328.

[4] Alan Trevennor. Practical AVR Microcontrollers. New York: Springer Science, 2012: 5-6.

[5] Cuno P. Getting Started with the Internet of Things. Gravenstein Highway North: O'Reilly Media, Inc. 2011: 11-13. 
[6] World Meteorological Organization. Guide to Meteorological Instruments and Methods of Observsation. Geneva, Switzerland: Chairperson, Publication Board. 2008: 155.

[7] Suradam, Mashaler. Perancangan Sistem Telemetri Akuisisi Data Cuaca Dengan XBee Pro-S2. Seminar Nasional Fisika. 2013. 